\title{
Using Religious Images to Teach Visual Literacy
}

\author{
A Unique Opportunity for Theological \\ Libraries
}

Daniel Smith, Garrett-Evangelical Theological Seminary

ABSTRACT Over the last few years, many publications have appeared that focus on ways of teaching visual literacy and its importance in research. Today's researchers must be equipped with the tools to interpret and make meaning from visual materials to succeed in their studies. The theological/religious world is uniquely well-suited for this discussion, as it already has much to offer in terms of familiar images and icons. These offerings are diverse and filled with much meaning and potential. This Listen and Learn session explored ways to use religious art as a way to teach visual literacy. The hope was that participants would leave with a clearer idea of visual literacy and the ways that theological libraries can engage and teach it to our students. By equipping our students with these skills, they will hopefully become more solid and informed in their scholarship and research and more comfortable using and engaging images.

\section{INTRODUCTION}

As a way of beginning the session, participants were invited to experience visio divina, a way of focusing upon a visual and meditating upon its spiritual potential. To center ourselves, we all took three deep breaths and then focused upon a specific image. The image that was chosen for the session was Van Gogh's “The Great Samaritan," painted in 1890. As we focused upon the image, we were given a series of prompts that invited us to focus upon what we saw initially, what the colors/lines might communicate, how God might be speaking to us through this painting, etc. As we continued to gaze at the painting, a reading of the Great Samaritan story from Luke 10:30-4 was read. We closed by looking at the painting in light of the Biblical narrative. 
With the end of this experience, I explained how my experience of visio divina prompted me to explore how this exercise might be used as a way of teaching visual literacy in theological education. Through my experience, I realized that I did not have adequate skills to engage deeply with images and, as a result, I began to explore how I might improve those. I have been compelled by the conversations about contemplative pedagogy and libraries, and I see this as a viable tool for our work in theological libraries, but I wonder how we might uniquely teach visual literacy and what the specific needs of theological students might be. We must explore this because, "Images often function as information, but they are also aesthetic and creative objects that require additional levels of interpretation and analysis" (ACRL 2011).

\section{PARTICIPANTS' EXPERIENCE}

Before moving into an exploration of visual literacy, participants were polled about their experience of visual literacy. They were asked if they had taught visual literacy and if they had any learning objects dedicated to visual literacy in their libraries. Most participants answer no to both of these questions. I also invited the participants to think about how they had seen images used in their institutions and whether they use images with intentionality. These questions and answers helped to organize the rest of the sessions, where I introduced the concepts of visual literacy.

\section{VISUAL LITERACY}

So, what exactly is visual literacy? In the words of the Association for College and Research Libraries (ACRL 2011):

Visual literacy is a set of abilities that enables an individual to effectively find, interpret, evaluate, use, and create images and visual media. Visual literacy skills equip a learner to understand and analyze the contextual, cultural, ethical, aesthetic, intellectual, and technical components involved in the production and use of visual materials. A visually literate individual is both a critical consumer of visual media and a competent contributor to a body of shared knowledge and culture.

Despite living in an increasingly visual culture, various researchers and librarians have found that most students do not know how to effectively engage with images and do not use images appropriately 
when they do. While they may incorporate images into presentations, students are particularly hesitant to use images in their papers (Matusiak, Heinbach, Harper, and Bovee 2019). Clearly, we cannot take visual literacy for granted and, as I have found, students are very interested in utilizing and engaging images in their coursework and ministries.

As identified in the quote from the ACRL, visual literacy involves distinct abilities. A visually literate person is able to find, interpret, evaluate, and use images. Librarians can help students become visually literate by focusing upon these abilities.

First, by focusing upon finding images, librarians can highlight places to look for visuals, like library databases and credible websites. They can also highlight effective search strategies that may help students better locate images. By describing how images are classified and labeled, librarians can help students better understand how to find images. As the ACRL (2011) states, "Finding visual materials in text-based environments requires specific types of research skills."

Next, we can focus upon the ways of interpreting images. Various conversations about the role of librarians in interpretation have concluded that this may best be reserved for disciplinary specialists, like professors; however, we can identify resources that may help students better understand the work of interpreting images.

Third, we can focus upon the act of evaluation, and we have much to offer in this regard. There are digital tools like InVid and Google Image Search that can be very helpful. They allow you to see if images have been altered and to see how images have been used by others. Participants were invited to share tools that they have used or recommended to others. They were also invited to share additional criteria that would be helpful for evaluating images.

Finally, we can teach students how to effectively use images as well. According to the ACRL's (2011) visual literacy standards, "The use, sharing, and reproduction of visual materials also raise particular ethical and legal considerations.” By discussing the ways that copyright and licensing interact with images, we can empower students with a keener sense of acceptable use. We can discuss the public domain, Creative Commons, fair use, and other concepts in this regard. We can also talk about image creation and the importance of associating metadata with images so that they are searchable and accessible to all. In addition, we can highlight the importance of 
appropriate citing images and giving credit so that folks can easily locate images later.

Images are a part of scholarly communication and have much to teach us when we engage them deeply. Like with any search process, these four steps are iterative and require a continual engagement through the research process. While I focused upon teaching visual literacy to students, this process can also be helpful with other constituencies, like faculty and staff, who also use images in their research and work.

\section{ADDITIONAL CONSIDERATIONS}

The work of teaching visual literacy is best done in partnership with others, like faculty and centers/committees. At Garrett-Evangelical, there are several faculty who are very interested in religious art and often incorporate it in their scholarship and teaching. Some even teach courses that focus upon religious art. They are clearly viable partners. Likewise, we have an Art Committee that works to display art and preserve the seminary's collections. I invited all of the participants to think about who might be partners for this work at their institutions.

The work of teaching visual literacy is also best accomplished with additional learning objects, like LibGuides or tutorials, which help students further explore how they can become visually literate. A guide can highlight image sources, tools, resources, etc. It can also help the students begin to critically engage images by presenting them with questions. I shared an example from our library's guide (bit.ly/stybergvl). Of course, it is also important to think about the ways that we might assess visual literacy. I shared some assessment ideas with the participants (bit.ly/vlassess).

\section{CONCLUSION}

In conclusion, I share this quote from the ACRL (2011):

Across disciplines, students engage with images and visual materials throughout the course of their education. Although students are expected to understand, use, and create images in academic work, they are not always prepared to do so. Scholarly work with images requires research, interpretation, analysis, and evaluation skills specific to visual materials. These abilities cannot be taken for 
granted and need to be taught, supported, and integrated into the curriculum.

Recognizing that we all come from various religious traditions, with various theologies and histories with religious art/images, I encouraged the participants to think about how they might teach visual literacy in their libraries. Images teach us, and we interact with them daily. We must learn to engage them deeply and recognize their potential within theological education. Perhaps spiritual practices like visio divina might be one way of beginning to do just that.

To learn more about visual literacy, I recommend Visual Literacy for Libraries: A Practical Standards-Based Guide (Brown et al. 2016). It is a very helpful, how-to introduction that includes various important questions to consider as well as exercises for the reader and teacher of visual literacy.

\section{WORKS CITED}

Association for College and Research Libraries. 2011. "ACRL Visual Literacy Competency Standards for Higher Education.” www.ala. org/acrl/standards/visualliteracy.

Brown, Nicole E., Kaila Bussert, Denise Hattwig, and Ann Medaille. 2016. Visual Literacy for Libraries: A Practical Standards-Based Guide. Chicago: American Library Association.

Matusiak, Krystyna K., Chelsea Heinbach, Anna Harper, and Michael Bovee. 2019. "Visual Literacy in Practice: Use of Images in Students' Academic Work.” College \& Research Libraries 80, no. 1: 123-39. doi.org/10.5860/crl.80.1.123. 